\title{
Trending topics in Spanish Palaeontology: Contributions from the XI Encuentro de Jóvenes Investigadores
}

\author{
Pilar NAVAS-PAREJO ${ }^{1,2} \&$ Carlos MARTÍNEZ-PÉREZ
}

${ }^{1}$ Estación Regional del Noroeste, Instituto de Geología, UNAM, 83000 Hermosillo, Mexico; pilarnpg@geologia.unam.mx
${ }^{2}$ Departamento de Estratigrafía y Paleontología, Universidad de Granada, 18071 Granada, Spain; png@ugr.es
${ }^{3}$ Departamento de Geologia, Universitat de Valencia, 46100 Burjassot (Valencia), Spain; Carlos.Martinez-Perez@uv.es

Navas-Parejo, P. \& Martínez-Pérez, C. 2015. Trending topics in Spanish Palaeontology: Contributions from the XI Encuentro de Jóvenes Investigadores. Spanish Journal of Palaeontology, 30 (1), 95-96.

Earth has experienced tremendous changes over the last 600 millions years. These changes, including climate and paleogeography changes have had important consequences on the biotas with great radiations or extinctions; changes that have been recorded and preserved in the geological record. Therefore, the understanding of this record is the primary goal of Palaeontology. This goal requires a multidisciplinary approach, including systematic, palaeogeographic, palaeoecologic and evolutionary studies that in a lower scale are represented in the special volume herein published.

The present volume represents a series of synthetic works presented at the XI Encuentro de Jóvenes Investigadores en Paleontología, which took place in Atarfe (Granada, Spain) on April 2013. During this meeting, more than thirty contributions were presented, offering a representative sample of the palaeontological state-of-the-art research currently developed in Spain. A small selection of these contributions is here presented, highlighting that most of them are firstauthored by early-stage Spanish researcher who attended the aforementioned meeting.

As stated above, our planet has evolved since its origin, in a similar way that Palaeontology has evolved during the last decades. This evolution, with the application of new novel ways to obtain accurate information from the past, combined with more traditional approaches, is patently showed by the contents of the following papers. Several of these papers deal with the application of recently developed techniques on palaeobiological studies. For example, Mujal et al. made several 3D models from Middle Triassic tetrapod footprints, using photogrammetry, which they used for morphological descriptions and depth analyses. Martínez-Pérez et al. performed histological analysis to a Triassic conodont species that suggests the existence of functional adaptations due to their slicing function. Marcé-Nogué et al. discussed different ways to generate an efficient mesh when performing Finite Element Analysis on vertebrates.

On the other hand, other papers here presented point out that there is still classic paleontological work to do. NavasParejo et al. described the first record of well-dated Upper Devonian and Lower Carboniferous deposits in the central sector of the Betic Cordillera (SE Spain). Blanco et al. presented new findings in the fossil record of the Upper Cretaceous of the South-Central Pyrenees (NE Spain), which include turtles, crocodiles, theropods and possible sauropod remains in addition to hadrosaurs. García-Vázquez et al. presented new radiocarbon datings of Ursus arctos L. (brown bear) from the Cantabrian Mountains (NNW Spain), which demonstrate the presence of this species in Spain from the Pleistocene to the early Holocene.

We would like to thank the early-stage researchers who have contributed to this volume, the senior researchers coauthoring the papers, and all the people and institutions that supported the successful celebration of the XI Encuentro de Jóvenes Investigadores en Paleontología. 
